\author{
RESEARCH ARTICLE \\ 10.1029/2018JC014539 \\ Key Points: \\ - We investigate the subdecadal \\ interaction between the NAO, and \\ the North Atlantic Ocean circulation \\ in a subset of CMIP5 models \\ - A distinct dipolar oceanic \\ overturning anomaly goes along \\ with anomalies in the North \\ Atlantic sea surface temperature and \\ gyre circulation \\ - Anomalous surface heat fluxes in \\ concert with anomalous vertical \\ motions drive a meridional dipolar \\ heat content anomaly in the upper \\ ocean
}

Supporting Information:

- Supporting Information S1

Correspondence to:

T. Martin,

tmartin@geomar.de

Citation:

Martin, T., Reintges, A., \& Latif, M. (2019). Coupled North Atlantic subdecadal variability in CMIP5 models. Journal of Geophysical

Research: Oceans, 124, 2404-2417.

https://doi.org/10.1029/2018JC014539

Received 14 SEP 2018

Accepted 18 FEB 2019

Accepted article online 20 FEB 2019

Published online 5 APR 2019

(c)2019. American Geophysical Union. All Rights Reserved.

\section{Coupled North Atlantic Subdecadal Variability in CMIP5 Models}

\author{
Thomas Martin $^{1}$ (D), Annika Reintges ${ }^{1}$ (D) and Mojib Latif ${ }^{1,2}$ (D) \\ ${ }^{1}$ GEOMAR Helmholtz Centre for Ocean Research Kiel, Kiel, Germany, ${ }^{2}$ Cluster of Excellence “The Future Ocean”, \\ University of Kiel, Kiel, Germany
}

Abstract The interaction between the atmosphere, specifically the North Atlantic Oscillation, and the North Atlantic Ocean circulation on subdecadal time scale is analyzed in a subset of models participating in the Coupled Model Intercomparison Project phase 5. From preindustrial control runs of at least 500-year length, we derive anomaly patterns in the atmospheric and ocean circulation and of air-sea heat exchange. All models simulate a distinct dipolar oceanic overturning anomaly at the subdecadal time scale, with centers at $30^{\circ} \mathrm{N}$ and $55^{\circ} \mathrm{N}$. The dipolar overturning anomaly goes along with marked anomalies in the North Atlantic sea surface temperature and gyre circulation. Lag-regression analyses demonstrate, with relatively small ensemble spread, how the atmosphere and the ocean circulation interact. The dipolar anomalies in the overturning are forced by North Atlantic Oscillation-related wind stress curl anomalies. Anomalous surface heat fluxes in concert with anomalous vertical motions drive a meridional dipolar heat content anomaly in the upper ocean, and it is this dipolar heat content anomaly which carries the coupled system from one phase of the subdecadal cycle to the other by reversing the tendencies in the overturning circulation. The coupled subdecadal variability derived from the Coupled Model Intercomparison Project phase 5 models is characterized by three elements: a wind-driven part steering the dipolar overturning anomaly, surface heat flux anomalies that support a heat buildup in the subpolar gyre region, and the heat storage memory which is instrumental in the phase reversal of the North Atlantic Oscillation.

Plain Language Summary The climate variability of the North Atlantic region is largely determined by interactions between atmosphere and ocean. The North Atlantic Oscillation in the atmosphere and variations in the oceanic meridional heat transport are key phenomena in the Atlantic sector and responsible for large fractions of variability. In the ocean, the meridional heat transport is closely related to the Atlantic meridional overturning circulation, and to the subtropical and subpolar gyres. We derive the interaction between the atmosphere and ocean, on the subdecadal time scale in a subset of 12 climate models. Here we find a distinct dipolar overturning anomaly with centers at $30^{\circ} \mathrm{N}$ and $55^{\circ} \mathrm{N}$ and a period between six and eight years. Marked anomalies in North Atlantic sea surface temperature and gyre circulation go along with the dipolar overturning variability. Anomalous wind fields in concert with anomalous vertical motions in the ocean changes the heat content pushed the coupled system from one North Atlantic Oscillation phase to the other. The subdecadal variability is characterized by three elements: a wind-driven part steering the overturning, surface heat flux anomalies supporting an oceanic heat buildup, and the heat storage memory which is instrumental in the phase reversal of the North Atlantic Oscillation.

\section{Introduction}

The climate variability of the North Atlantic region is largely determined by thermodynamic and dynamic interactions between the atmosphere and the ocean. The North Atlantic Oscillation (NAO) in the atmosphere and variations in the oceanic meridional heat transport (MHT) are key phenomena in the Atlantic sector and responsible for an appreciable amount of variability on a variety of time scales. The NAO index is a measure of the large-scale pressure gradient in the atmosphere between the Azores high and the Icelandic low (Hurrell, 1995; Hurrell \& Deser, 2010; Visbeck et al., 2001) characterized by the storm track variability over the Atlantic sector from subseasonal to multidecadal time scales (Hurrel and Deser, 2010). In the North Atlantic, the MHT is closely related to the Atlantic meridional overturning circulation (AMOC) and to a lesser extent the subtropical and subpolar gyres (STG and SPG, respectively; Buckley \& Marshall, 2016). The AMOC transports relatively warm and salty surface water northward, which is compensated by a deep return flow of colder and fresher water. AMOC variability accounts for a major part of 
the MHT variability in the North Atlantic on multidecadal time scales. In climate models, periods of a persistent positive NAO index drive stronger AMOC and MHT which in turn drive positive sea surface temperature (SST) anomalies over the North Atlantic. The AMOC is sensitive to density changes at high northern latitudes. A positive phase of the NAO strengthens the AMOC by extracting heat from the subpolar gyre, thereby increasing deepwater formation and horizontal density gradients (Delworth et al., 1993; Delworth et al., 2017; Delworth \& Zeng, 2016). A coupled driving mechanism steering the AMOC and the NAO seems possible (e.g., Timmermann et al., 1998). However, it is controversial to which extent AMOC variability feeds back on the NAO, and if so at which time scale. Within the near-surface ocean layers, the STG and the SPG contribute additional variability to the MHT.

Observations from the Rapid Climate Change (RAPID) mooring array at $26.5^{\circ} \mathrm{N}$, which started in 2004, depict an interannual variability of several sverdrups in the meridional overturning and MHT (Cunningham et al., 2007; Smeed et al., 2015). At interannual to decadal time scales, which is the focus of this study, the variability of the coupled atmosphere-ocean system over the North Atlantic is largely determined by the exchange of momentum and heat at the sea surface (Delworth \& Greatbatch, 2000). The NAO-related atmospheric circulation anomalies, for example, drive large air-sea heat exchange anomalies, which determine the storm activity over the North Atlantic Ocean (Allison et al., 2015; Hurrell \& Deser, 2010). Heat gain from the ocean is associated with intensified atmospheric cyclogenesis, indicating a high NAO-index phase.

The nature of the interactions between the atmosphere and the ocean strongly depend on time scale (Bjerknes, 1964; Gulev et al., 2013). As described above, oceanic heat loss in the subpolar North Atlantic supports deepwater formation and relates to AMOC variability. A prominent part of the overturning variability that originates in the SPG region propagates southward. The signal reaches the equator after about 5 to 10 years (Zhang, 2010; Zhang \& Zhang, 2015). Due to the wind stress the SPG and the overturning are closely related: on short interannual time scales due to NAO-related wind stress anomalies (Born \& Mignot, 2012), on the longer decadal to multidecadal time scales due to NAO-related buoyancy forcing (Deshayes \& Frankignoul, 2008; Eden \& Jung, 2001). We note that the bottom pressure torque represents a key dynamical link between the overturning and the SPG (Yeager, 2015). Álvarez-García et al. (2008) derive from sea surface temperature (SST) observations two distinct oscillatory modes in the North Atlantic, which are associated with a multidecadal and a quasidecadal period. The multidecadal mode of SST is the Atlantic Multidecadal Oscillation/Variability (Knight et al., 2005) and is linked to basin-wide AMOC variability, where the AMOC has been obtained from a forced ocean model simulation. This study is concerned with the shorter time scale variability, specifically that on the subdecadal time scale, which involves a tripolar SST anomaly, resembling the NAO imprint, and a dipolar overturning anomaly.

The relative importance of individual steering mechanisms of subdecadal ocean-atmosphere variability in the North Atlantic sector is still under discussion. For example, Arctic sea ice (Deser \& Blackmon, 1993), the advection by the mean ocean circulation (Sutton \& Allen, 1997), the wind-driven ocean circulation (Czaja \& Marshall, 2001; Marshall et al., 2001), the overturning circulation (ÁlvarezGarcía et al., 2008; Eden \& Greatbatch, 2003), and the stochastic resonance mechanism (Saravanan and McWilliams, 1997, 1998) have been proposed as important drivers of North Atlantic subdecadal variability. When neglecting any advection the North Atlantic SST anomalies can be understood as the time-integrated response to NAO-related surface heat flux anomalies. However, thermal anomalies are not restricted to the sea surface and could extend to depths of 1-2 km, implying an advective origin (Williams et al., 2015). Thermal anomalies in the SPG often have an opposing sign to the subtropics and are linked in both regions to heat convergences associated with the meridional overturning circulation (Williams et al., 2014 and 2015). Observations indicate a heat content subdecadal dipolar signal in the ocean between SPG and STG, which lags the NAO index by two to three years (Curry \& McCartney, 2001). The variability of ocean heat convergence and surface heat flux might affect atmospheric variability and in turn the wind-driven part of the meridional overturning (Barrier et al., 2015).

This study has been motivated by the study of Reintges et al. (2017), in which, by analyzing observations and one climate model, the subdecadal NAO variability is suggested to originate from dynamical large-scale airsea interactions. Here we investigate the subdecadal NAO and meridional overturning variability as well as the related atmospheric and oceanic variability in preindustrial control integrations of 12 models participating in the Coupled Climate Model Intercomparison Project phase 5 (CMIP5). Section 2 provides information 


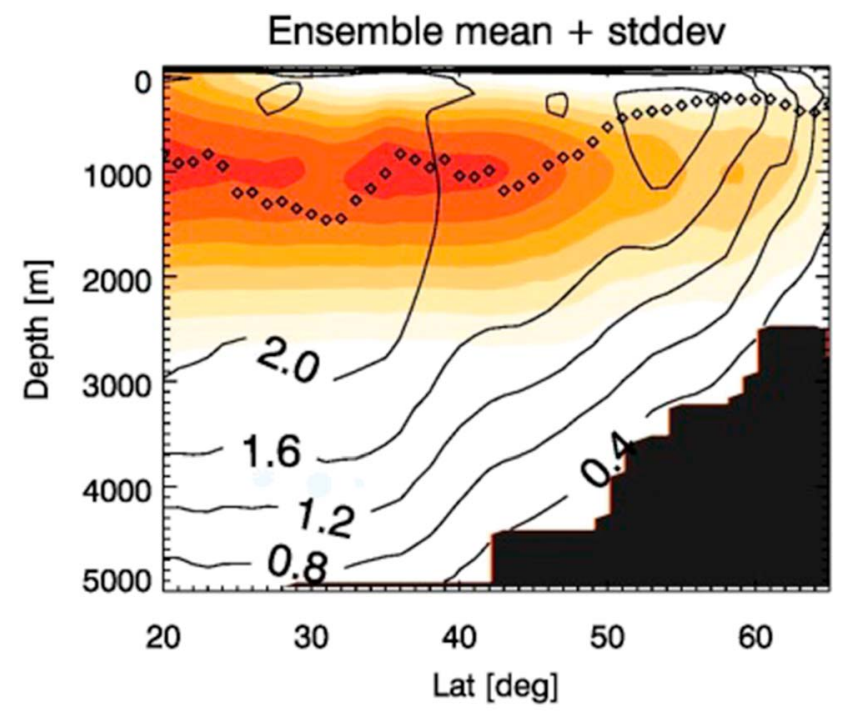

[Sv]

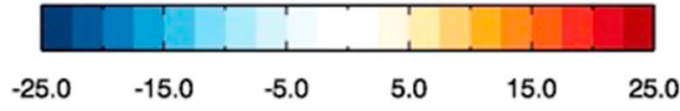

Figure 1. The ensemble-mean January-March (JFM) Atlantic meridional overturning stream function (color shading) and the ensemble-mean temporal standard deviation (STD; contours) in Sv. The symbols indicate the ensemble-mean depth of the maximum STD. about the model ensemble, the experimental setup, and the statistical methods for the identification of the subdecadal variability in the different data sets. In section 3, we present the common physics behind the subdecadal variability in the CMIP5 models. Summary of the major findings and main conclusions are presented in section 4 .

\section{Data and Methods}

We use climate model simulations assembled in the framework of the World Climate Research Programme's Climate Model Intercomparison Project phase 5 (CMIP5; Taylor et al., 2012). All data are provided by the Program for Climate Model Diagnose and Intercomparison. Here we diagnose data from the preindustrial control (piControl) simulations with a constant $\mathrm{CO}_{2}$ concentration representing the year 1850 with $285 \mathrm{ppm}$ (Meinshausen et al., 2011). For 12 models (Table S1), which provide simulations of at least 500-year length and a full set of parameters, we analyze the annual-mean and late-winter mean (January-March) values.

A number of indices are employed in this study. Overturning stream function indices at $30^{\circ} \mathrm{N}(\psi 30 \mathrm{~N})$ and at $55^{\circ} \mathrm{N}(\psi 55 \mathrm{~N})$ are defined at the depth of the corresponding long-term maximum (Figure 1). We denote the negative of the overturning index at $55^{\circ} \mathrm{N}$ by $\psi 55 \mathrm{~N}(-1)$. Parameters of SPG region are indexed with their spatial means within the location $45^{\circ} \mathrm{N}-65^{\circ} \mathrm{N}$ and $60^{\circ} \mathrm{W}-15^{\circ} \mathrm{W}$. We calculate an NAO index from sea level pressure (SLP) as the difference of the normalized SLP anomalies averaged over $60^{\circ} \mathrm{N}-70^{\circ} \mathrm{N}$ and $35^{\circ} \mathrm{N}-45^{\circ} \mathrm{N}$ and zonally between $40^{\circ} \mathrm{W}$ and $0^{\circ}$. Local regression coefficients on different indices are computed, where the indices are normalized by their standard deviations (STD).

As the focus of this study is on subdecadal to decadal time scales, we apply in some of the analyses band-pass filtering to the indices retaining variability between 5 and 15 years. Various filters with slightly different bandwidths have been used but the results are not sensitive to the selected thresholds. A digital filter following Walraven (1985) is used. In the calculation of the confidence limits for the correlation coefficients, we use a $t$ test based on the effective number of degrees of freedom, which is estimated from the decorrelation time of the band-pass-filtered time series (Leith, 1973). The decorrelation time is defined here as the $e$ folding time scale of the time series' autocorrelation function. In the power spectra we provide the relaxation time $\tau_{e}=1 / \lambda$, with the feedback parameter $\lambda$ calculated as a discrete fit to a corresponding first-order Markov process (Lemke et al., 1980).

\section{Results}

The ensemble-mean January-March Atlantic meridional overturning stream function calculated from the 12 CMIP5 models (Figures 1 and S1a) depicts a maximum within the region $30^{\circ} \mathrm{N}$ to $45^{\circ} \mathrm{N}$ around 1,000 $\mathrm{m}$ depth. Model uncertainty causes a large ensemble spread with respect to the value and latitudinal variation of the maximum (Figure S1a). Nevertheless, the long-term ensemble mean (Figure 1) is close to that obtained from the RAPID array at $26.5^{\circ} \mathrm{N}$ amounting to $17.5 \mathrm{~Sv}$ during 2004-2012 (Smeed et al., 2014). However, interannual variability in the observations is large. In the models, the depth of the absolute maximum (not shown) ranges from $792 \mathrm{~m}$ (CanESM2) to 1,203 m (FGOALS-s2), which is reasonable when compared to the depth of $1,100 \mathrm{~m}$ at $26^{\circ} \mathrm{N}$ derived from the RAPID data (Smeed et al., 2014).

The temporal STD of the stream function, amounting to typically $1 \mathrm{~Sv}$, varies considerably among models and with latitude (Figure S1b). During January-March, interannual variability increases (Figure S1c) at all latitudes and the depth of maximum variability shifts upward in the northern part of the overturning cell (Figure 1), which may reflect the importance of atmosphere-ocean coupling. 
In the model ensemble analyzed here, the variability of the NAO and of the overturning is linked. The correlation between the unfiltered NAO index and $\psi 55^{\circ} \mathrm{N}$ ranges from -0.33 (ACCESS1-3) to -0.84 (CNRMCM5), where more than $40 \%$ of the total variability in $\psi 55 \mathrm{~N}$ is accounted for in seven models (Table S2; lag $=0$ year, total).

The regression patterns of the overturning stream function on the NAO index (Figure 2a) depict a welldeveloped dipolar structure with a node near $40^{\circ} \mathrm{N}$ across all ensemble members. The ensemble-mean regression pattern is shown in Figure $2 \mathrm{~b}$. To test its robustness, we calculate at each location the ratio between the ensemble-mean regression coefficients and the corresponding ensemble spread (STD). The ratio is larger than 2 over a large part of the overturning stream function anomaly pattern (black solid contour in Figure $2 b$ ), providing some confidence in the ensemble-mean regression pattern.

The spectral distribution of the variability in the two overturning indices (Figures 3a and 3b) and in the NAO index (Figure 3c) is relatively flat, with the exception of $\psi 30^{\circ} \mathrm{N}$ depicting a marked increase in variance on longer than decadal time scales and $\psi 55 \mathrm{~N}$ depicting enhanced variance on subdecadal time scale. In contrast, the spectrum of the upper ocean (0-500 m) heat content in the subpolar gyre region, HC (SPG), exhibits a pronounced redness (Figure 3d). With respect to a best fit of the spectra to a first-order Markov process, which also are shown in Figure 3, the ensemble-mean spectra of $\psi 55 \mathrm{~N}$ and HC (SPG) depict a statistically significant peak at a period close to eight years. However, the spread among the individual models is large. The fit to an AR1 process (Lemke et al., 1980) yields the relaxation time $\tau_{e}$ [year] $=1 /\left(1-r_{1}\right)\left(r_{1}\right.$ is the autocorrelation at lag = 1 year), which amounts to four to five years for HC (SPG) and about one year for the NAO index and the two overturning indices.

Cross-spectrum analysis, expressed in terms of the amplitude, phase, and coherence spectrum, illustrates the relationships between the NAO index, HC (SPG), and $\psi 55 \mathrm{~N}$ (Figures 4 and S2; for individual models, see Figures S3-S5). Given the dipolar structure of the overturning anomalies and the particularly strong anomalies in the high latitudes (Figure 2), we use in the cross-spectrum analysis the negative of the overturning index at $55^{\circ} \mathrm{N}$ denoted by $\psi 55 \mathrm{~N}(-1)$. The amplitude spectrum between the NAO index and $\psi 55 \mathrm{~N}(-1)$ exhibits a significant covariance on subdecadal time scales (Figure 4a, left panel; the coherence spectra are shown in Figure S2). For periods shorter than five years, the NAO index and $\psi 55 \mathrm{~N}(-1)$ are in phase, which is consistent with the meridional overturning anomaly patterns (Figure 2). Between 5 years and 15 years (marked by the dashed vertical lines in the right panels), there is a phase lag such that $\psi 55 \mathrm{~N}$ $(-1)$ leads the NAO index. However, the phase angle between the two indices in this spectral interval is small and corresponds to a lag shorter than one year (Figure 4a, right panel). The NAO index and HC (SPG) show enhanced covariance from subdecadal to decadal time scales (Figures $4 \mathrm{~b}$ (left panel) and S4). In the ensemble mean and in the majority of the models the phase angle between HC (SPG) and NAO index is in the range $180^{\circ}$ to $-90^{\circ}$, indicating an $\mathrm{HC}(\mathrm{SPG})$ maximum prior to an NAO (+) phase while the heat content decline is strongest close to the NAO maximum. Alternatively, the phase difference can be interpreted as an $\mathrm{HC}$ minimum occurring prior to an NAO (-) phase. In any case, a phase shift between $180^{\circ}$ and $-90^{\circ}$ indicates that a tendency in the NAO is preceded by a tendency in $\mathrm{HC}$ of the same sign. The amplitude spectrum between $\mathrm{HC}(\mathrm{SPG})$ and $\psi 55 \mathrm{~N}(-1)$ depicts a highly significant peak in the range 5 years and 15 years (Figure 4c). A peak in this range is also present in the variance spectra of the two indices and in the coherence spectrum between them (Figures 3b, 3d, and S2c). HC (SPG) and $\psi 55 \mathrm{~N}(-1)$ are linked in the range 15 to 5 years with a phase shift of about $90^{\circ}$, indicating that $\mathrm{HC}$ (SPG) leads $\psi 55 \mathrm{~N}$ (-1; Figure 4c, right panel). We note that the relationships between the NAO index and the ocean indices in spectral domain are calculated from the unfiltered time series. Thus, the above findings are not influenced by filtering effects which have been discussed in Cane et al. (2017). The results suggest a time scale dependence of ocean-atmosphere interactions over the North Atlantic, which motivates us to investigate the relationships between NAO and ocean variability for selected frequency ranges.

Figure 5 shows the lag regressions of the overturning stream function upon the NAO index, in which only ensemble means have been used. We investigate the relation in four different bands: when the NAO index is not filtered, that is, retaining all variability (Figure 5a), and when retaining variability on time scales longer than 15 years (Figure 5b), between 5 and 15 years (Figure 5c), and shorter than 5 years (Figure 5d). Negative lags indicate that the overturning anomalies lead the NAO index. At lag 0 year, the anomaly patterns look very similar in all four bands. The regressions with the unfiltered NAO 


\section{a.)}
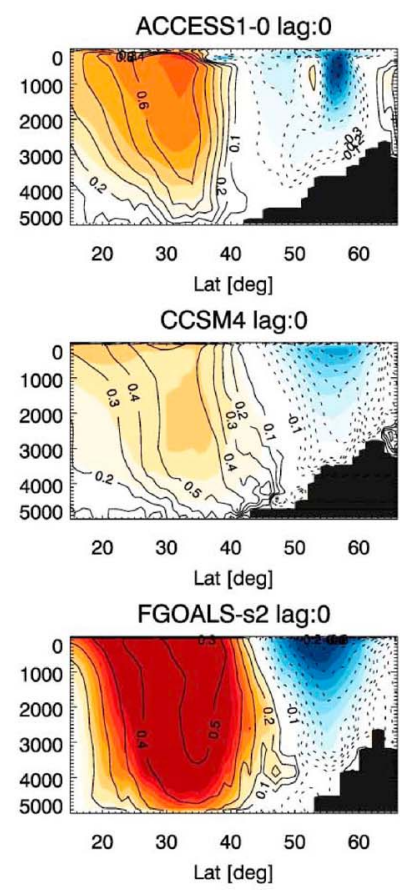

MPI-ESM-P lag:0

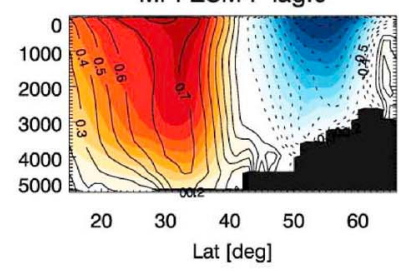

b.)

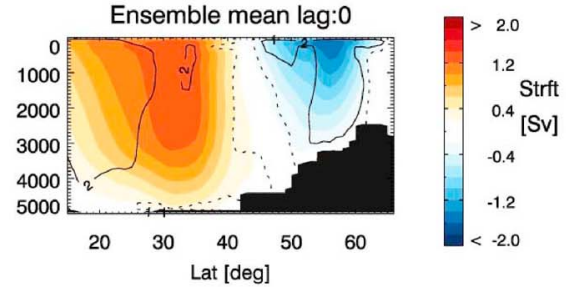

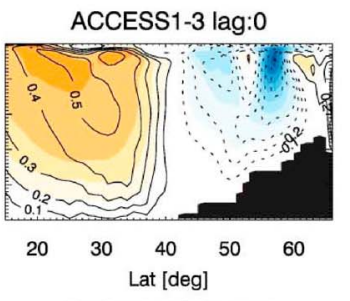

CESM1-BGC lag:0

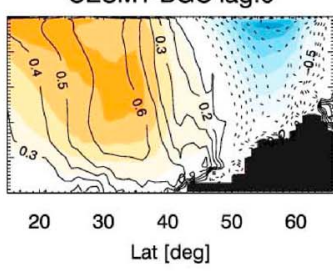

MPI-ESM-LR lag:0

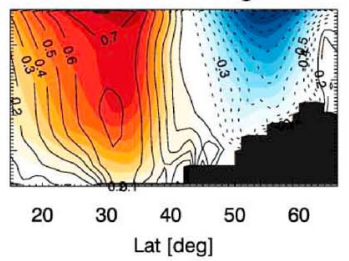

MRI-CGCM3 lag:0
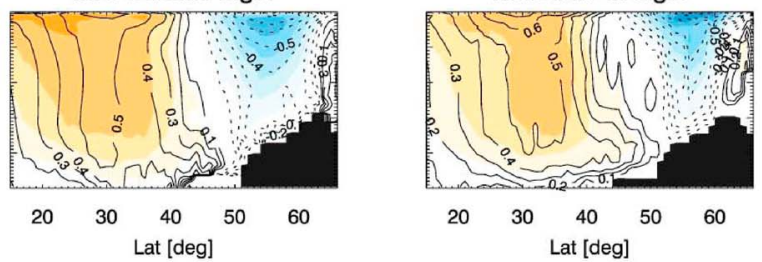

Figure 2. Regression of the overturning stream function (JFM) upon the unfiltered NAO index (JFM): (a) regression coefficient (color shading) for each ensemble member (the model name is given in the title of each panel), the correlation coefficients are shown as contours (solid for positive values and dashed for negative values), and (b) the ensemble mean of the regression coefficient (color shading). The ratio between the ensemble-mean regression coefficient and the model spread is given for the ratios of 1 (dashed contours) and 2 (solid contours).

index do not depict any signal in the overturning stream function prior to the NAO-index maximum (Figure 5a). However, weak positive anomalies occur in the north until two years after the NAO-index maximum. The NAO variability on time scales longer than 15 years is associated with an overturning stream function anomaly that is basically monopolar with its maximum near $30^{\circ} \mathrm{N}$. The overturning regressions increase from negative lags up to lag 1 year and weaken thereafter but stay relatively large at longer lags. Such an evolution of the overturning stream function has been observed in many climate models with regard to the AMOC variability on multidecadal time scale. Considering time scales between 5 and 15 years yields a subdecadal dipolar anomaly pattern in the overturning with a period of about 8 years (Figure 5c). A similar but weaker manifestation of this dipolar overturning 

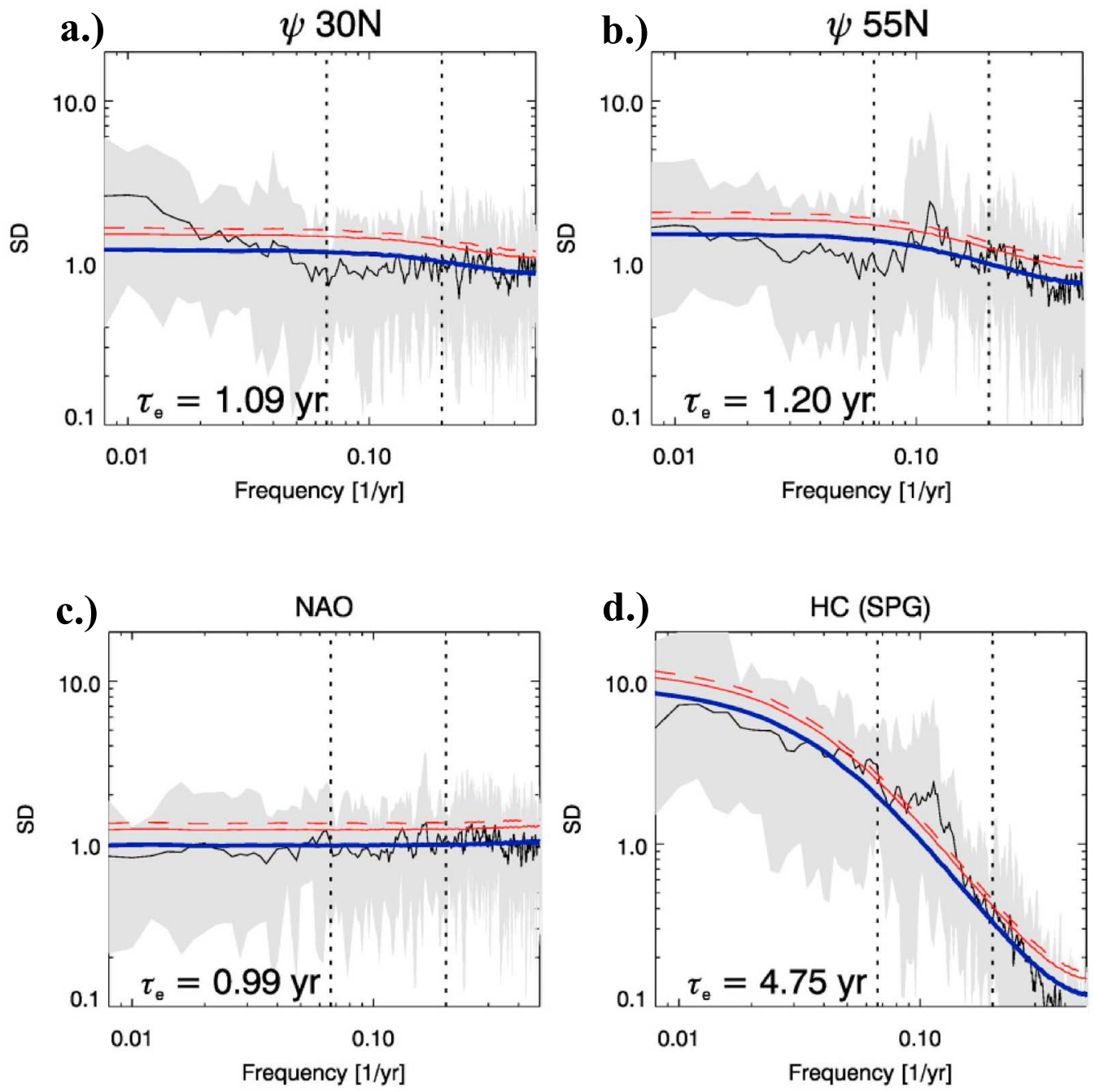

Figure 3. Spectra of the overturning (JFM) index at (a) $30^{\circ} \mathrm{N}$ and (b) $55^{\circ} \mathrm{N}$, (c) the NAO index (JFM), and (d) the ocean heat content (JFM) of the upper $500 \mathrm{~m}$ in SPG region. Shown are the ensemble range of the 12 CMIP5 models (gray shading) and the ensemble-mean spectra (black lines). The spectral density (SD) is normalized with the standard deviation of the index. The bold blue line indicates the fitted red-noise spectra with a 95\% (red, solid) and 99\% (red, dashed) confidence interval. The relaxation time $\tau_{e}$ (years) obtained by a fit to an AR1 process is given as $1 /\left(1-r_{1}\right)$, where $r_{1}$ is the autocorrelation at lag $=1$ year. The frequency band of $5-15$ years is marked by dashed black lines.

variability appears when retaining NAO-index variability on time scales shorter than five years but with a quasi-biennial period (Figure 5d), consistent with the study of Hurrell and van Loon (1997) describing biennial NAO variability.

We focus during the remainder of the paper on the subdecadal time scale. In order to get insight into the common dynamics of the subdecadal variability across the model ensemble, we present in the following ensemble-mean lag-regression patterns of selected variables onto the band-pass-filtered (retaining variability in the range 5-15 years) NAO index (Figures 6, 7, and S6). Based on the temporal relationships between the oceanic and atmospheric anomalies derived from the spectral covariability distribution (Figure 4) and the relatively symmetric evolution of the overturning anomalies in the lag regressions (Figure 5), we mainly focus in the following on the phases after the NAO maximum. The regression analyses yield an average cycle length of about eight years. As expected, the lag regressions of the SLP (Figure 6a) between lag -1 year and lag +1 year depict the positive phase of the NAO, which hereafter are termed NAO (+) years. A very similar 

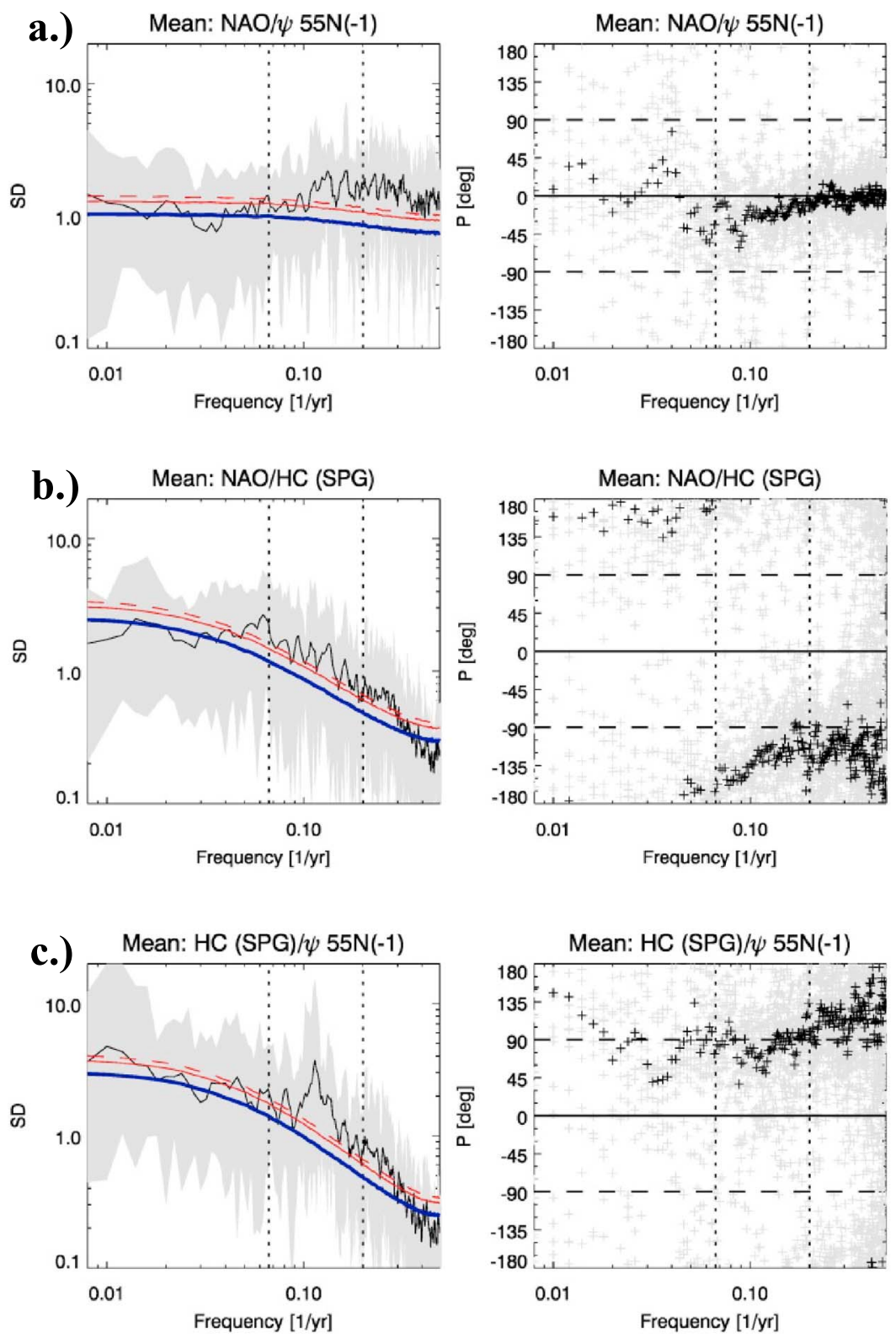

Figure 4. Cross-spectrum analysis between selected indices. The (left) ensemble-mean amplitude and (right) phase spectra between (a) the NAO index and $\psi 55 \mathrm{~N}$, (b) the NAO index and HC (SPG), and (c) between HCPG) $\psi 55 \mathrm{~N}$. The panels show the ensemble range of the 12 CMIP5 models (gray shading) and the ensemble-mean spectra (black line). The spectral density (SD) is normalized with the standard deviation of the index. The bold blue line indicates the fitted red-noise spectrum with a 95\% (red, solid) and 99\% (red, dashed) confidence interval. The frequency band of 515 years is marked by dashed black lines. Positive phase values in the right panels of (a) and (b) mean that the NAO index is leading, and in (c) that $\mathrm{HC}$ (SPG) is leading.

SLP anomaly pattern but with opposite signs is obtained with a lag of three and four years, which hereafter are termed NAO (-) years. The SLP anomaly patterns NAO (+) and NAO (-) imply zonal surface wind extrema in the region $40^{\circ} \mathrm{N}$ to $60^{\circ} \mathrm{N}$.

During NAO (+) years, the wind stress curl (Figure 7a) depicts large negative values between $40^{\circ} \mathrm{N}$ and $55^{\circ} \mathrm{N}$, and a zonal band of positive values north of $60^{\circ} \mathrm{N}$. A similar pattern but with opposite signs is observed during NAO (-) years. During NAO $(+)$ years the negative wind stress curl anomalies drive anomalous oceanic 


\section{a.)}
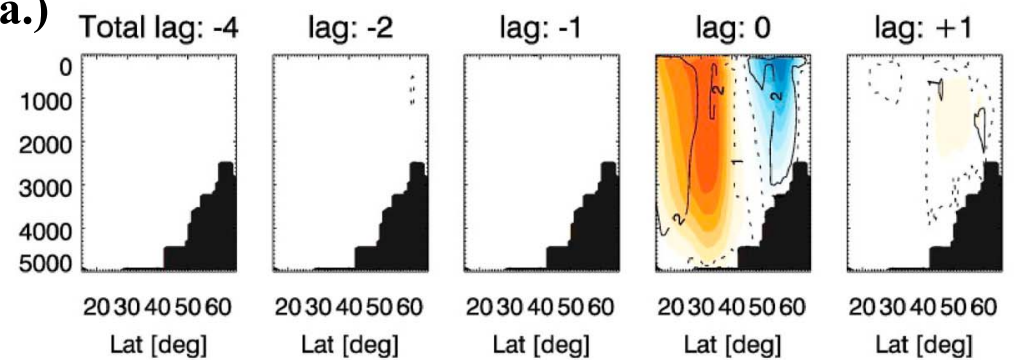

2030405060

Lat [deg]

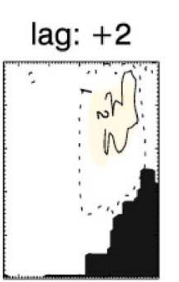

2030405060

Lat [deg]

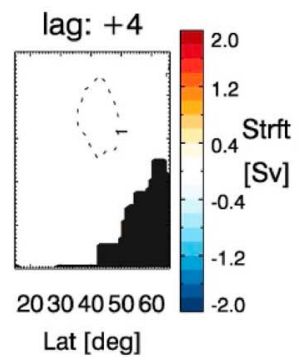

b.)

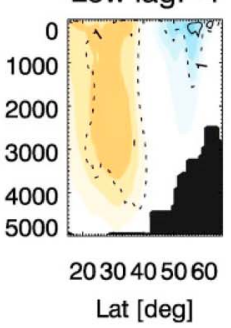

lag: -2
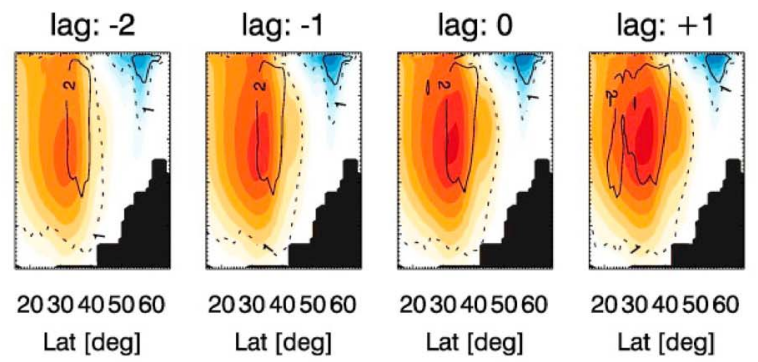

2030405060

Lat [deg]
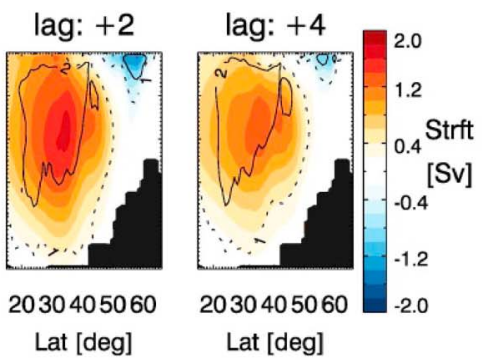

c.) Band lag: -4
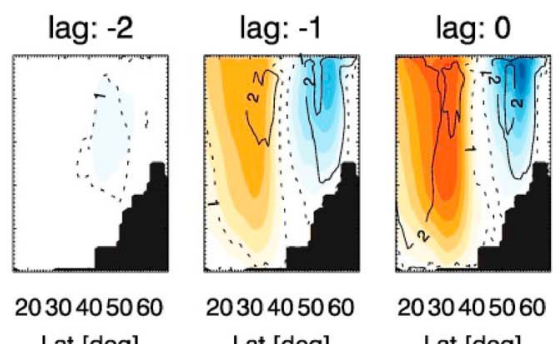

lag: +1
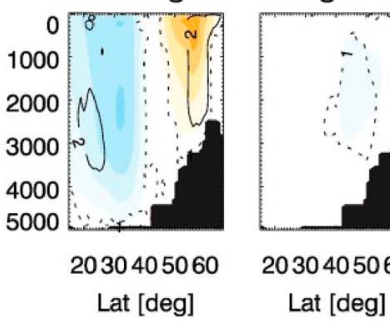

Lat [deg]
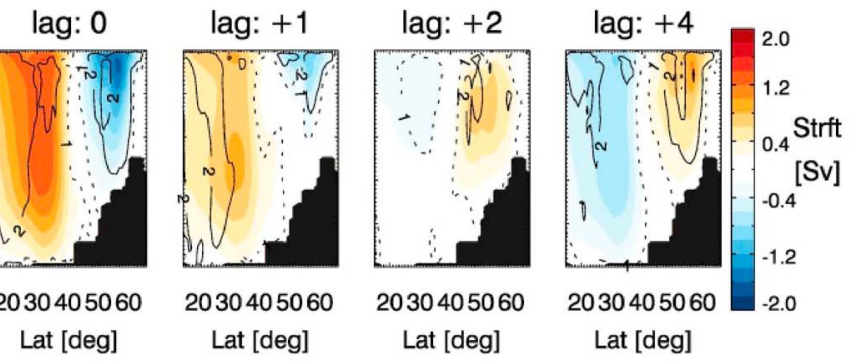

d.)
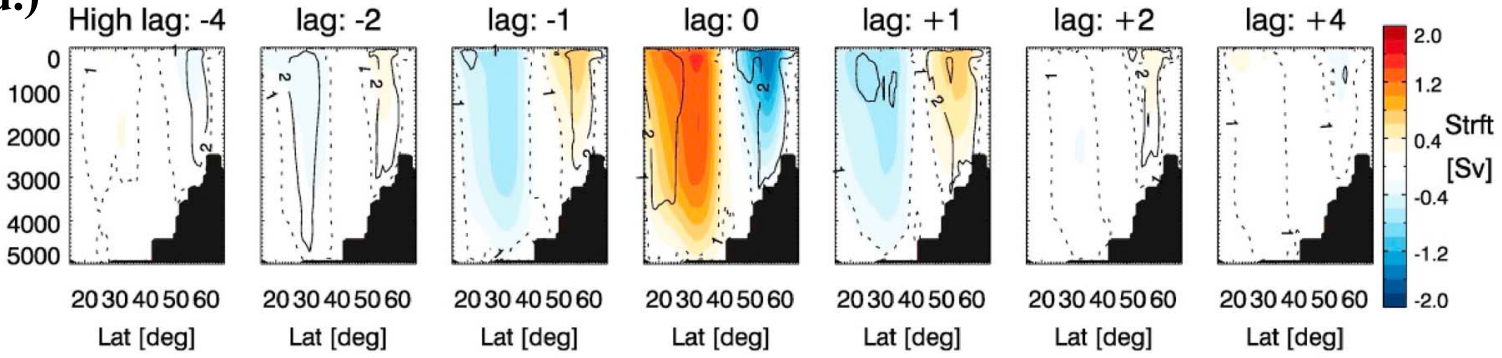

Figure 5. Ensemble-mean overturning stream function (JFM) lag regressions upon the NAO index (JFM), where (a) the NAO index is unfiltered or represents variability on time scales (b) longer than 15 years, (c) between 5 and 15 years, and (d) shorter than 5 years. Each subpanel shows the regressions for a lead time (years) relative to NAO index. Negative years indicate that the NAO index is lagging. The ratio between the regression coefficient and the model spread is given for the ratios of 1 (dashed contours) and 2 (solid contours).

convergence and downward motion in the region $40^{\circ} \mathrm{N}-55^{\circ} \mathrm{N}$, and anomalous divergence and upward motion during NAO (-) years. The corresponding regressions of the meridional surface current component exemplify this (Figure 7c). Consistent with the wind stress curl forcing, the lag regressions of the overturning stream function onto the NAO index (Figure 5c), which is reproduced in Figure 6b, reveal well-developed dipolar variability with a node near $40^{\circ} \mathrm{N}$. During NAO (+) years, anomalous northward mass and heat transport in the upper ocean layers is implied at midlatitudes and anomalous southward mass and heat transport farther to the north. The anomalous overturning cells extend over the entire water column. Such type of dipolar overturning variability is fairly consistent among the ensemble members, as indicated by the ratio of the regression coefficient and the ensemble spread (contours), a measure of the signal-to-noise ratio. This ratio, representing model agreement, exceeds a value of 1 in the southern pole and a value of 2 in the northern pole of the overturning dipole. 
a.)

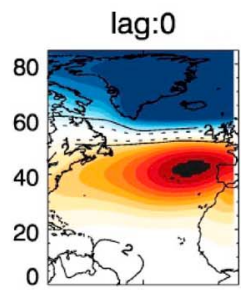

280

lag:0

b.)

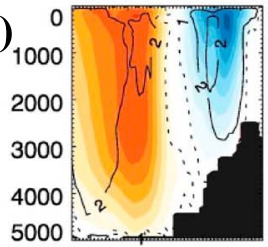

2030405060 Lat [deg]

lag:0

c.)
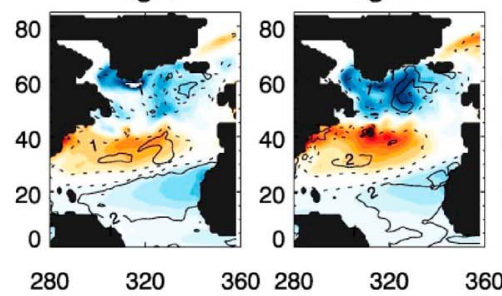

2030405060 Lat [deg] lag: +1

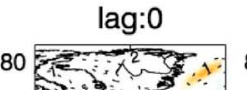

d.)
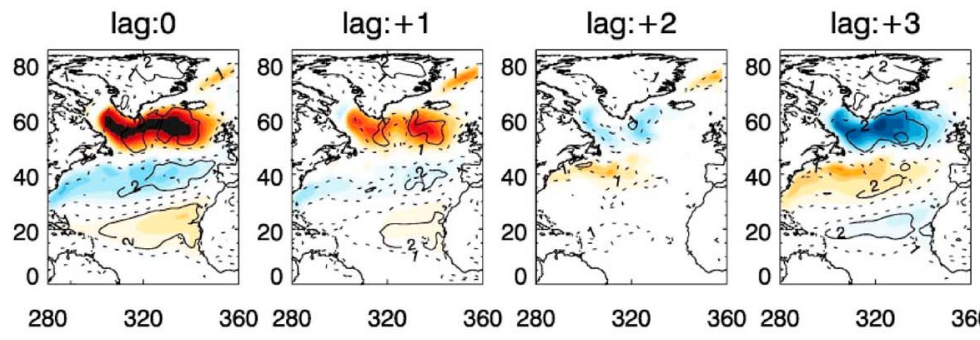

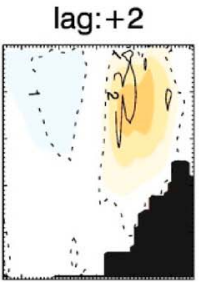

2030405060 Lat [deg] lag: +2
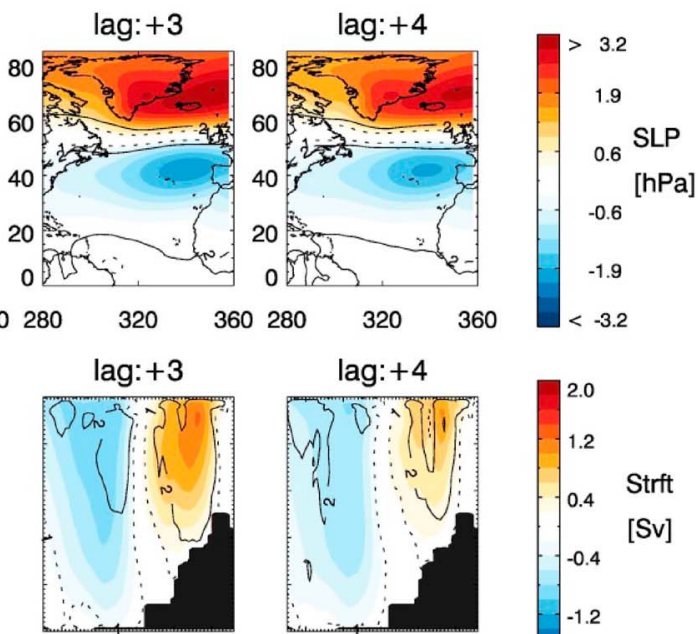

2030405060 Lat [deg]

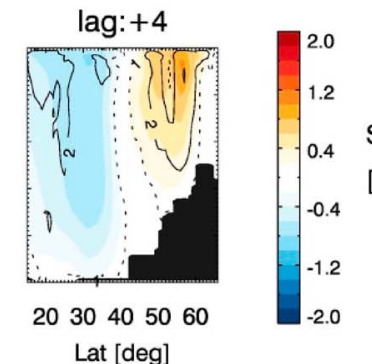

lag: +3
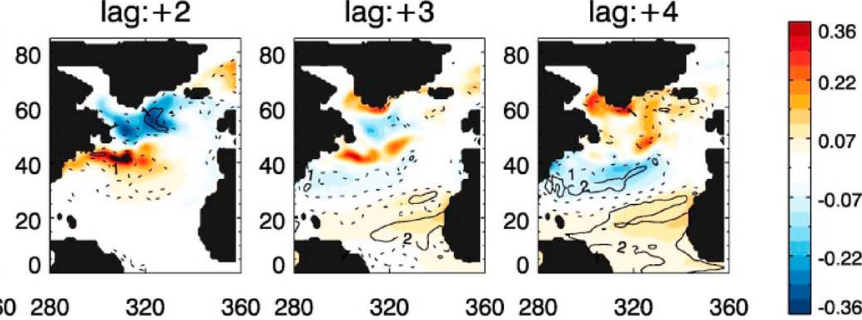

lag:0

lag: +1

e.)
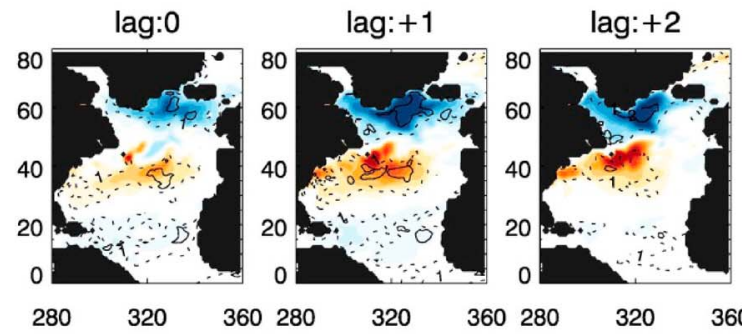

lag: +3
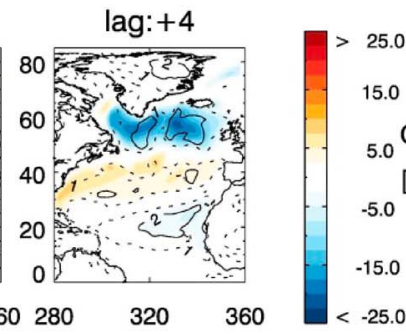

15.0

${ }_{5.0} \mathrm{OHL}$

$\left[\mathrm{W} / \mathrm{m}^{2}\right]$

$-5.0$

$-15.0$

$<-25.0$
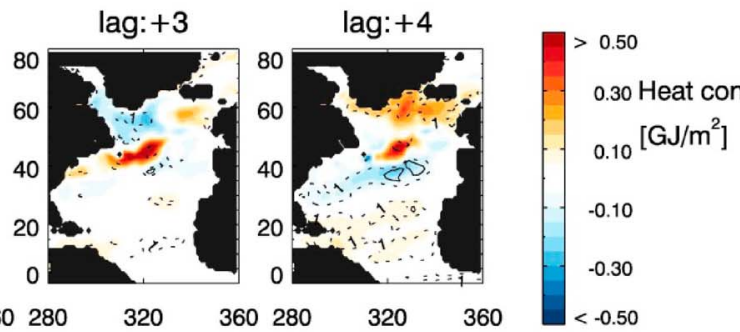

Figure 6. Ensemble-mean lag regressions of selected quantities (JFM) upon the band-pass-filtered NAO index (retaining variability between 5 and 15 years): (a) SLP, (b) meridional overturning stream function, (c) SST, (d) oceanic heat loss, and (e) upper ocean heat content (0-500 m). Each subpanel shows the regressions for a lead time (years) relative to NAO index. Positive years indicate that the NAO index is leading. The ratio between the regression coefficient and the model spread is given for the ratios of 1 (dashed contours) and 2 (solid contours).

The lag regressions of the BSF (Figure 7b) show a strong positive anomaly centered in the North Atlantic during NAO (+) years, which indicates a contraction and weakening of the SPG. We note that the positive BSF anomaly superimposes the climatological mean BSF which is negative in the SPG (shown for individual models in Figure S6a). The BSF regression pattern implies a poleward shift and a strengthening of the Gulf Stream/North Atlantic Current system. During NAO (-) years, a similar regression pattern with opposite signs occurs. Relative to the climatology, the Gulf Stream/North Atlantic Current part of the BSF 
a.)

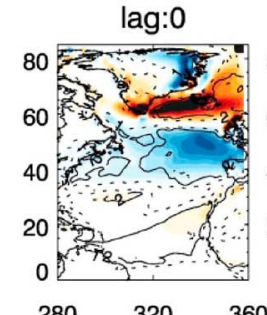

280
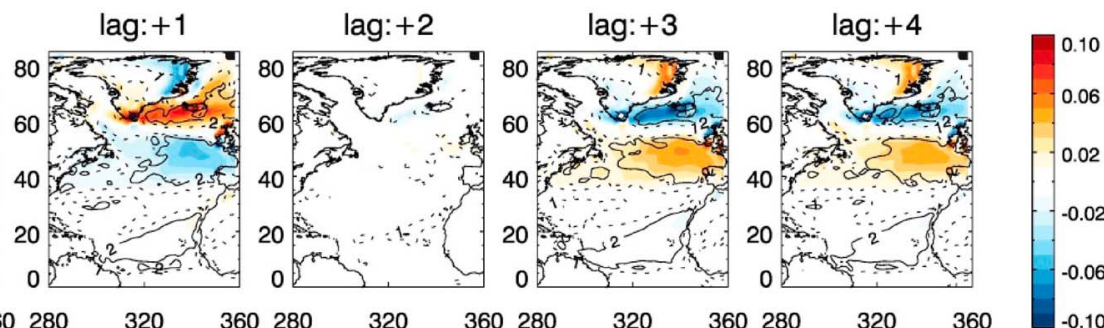

Curl $\left[\mathrm{N} / \mathrm{m} * 10^{-6}\right]$

lag:0

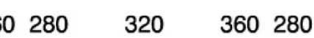

320

360280

320
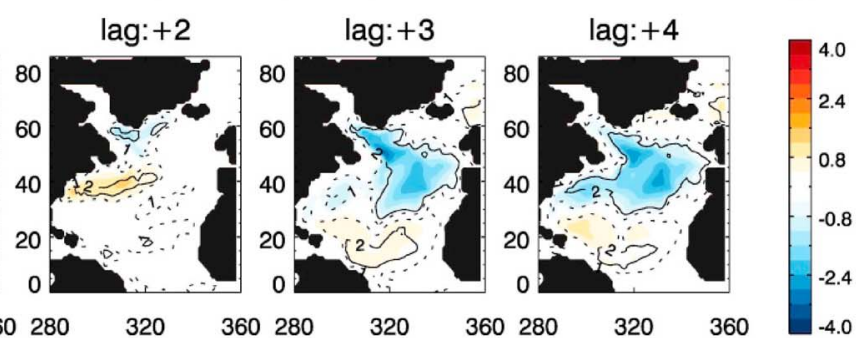

barot. strft

[Sv]
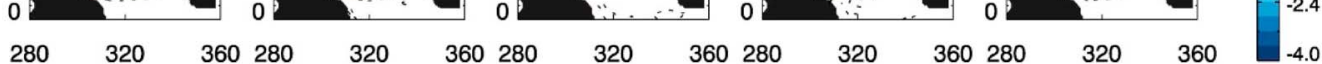

360280

$320 \quad 360280$

lag: +2
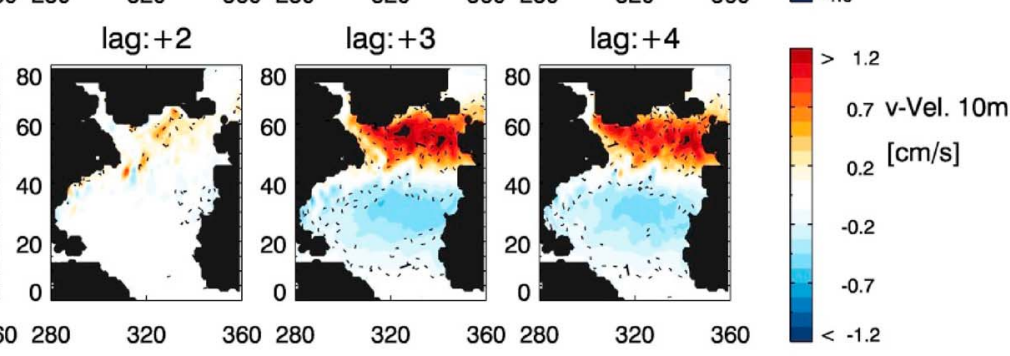

Figure 7. Same as in Figure 6 but for (a) wind stress curl, (b) barotropic stream function, and (c) meridional ocean velocity component at 10 m.

regression pattern reflects the "intergyre" gyre (Marshall et al., 2001). In both NAO (+) and NAO (-) years, the ratio of regression coefficient and ensemble spread attains values larger than 2 in the subtropical and subpolar North Atlantic. The anticyclonic (positive) BSF anomaly during NAO (+) years goes along with convergence in its center, which is physically consistent with the overturning stream function anomaly. During NAO (-) years, the BSF anomalies imply a southward extension of the SPG.

The NAO (+) years are characterized by a tripolar SST anomaly pattern (Figure 6c) with a cold anomaly in the SPG region, a warm anomaly in the midlatitudes and another cold anomaly in the tropics. The SST anomalies in the SPG and midlatitudes persist until lag 2 years. The overturning anomalies, on the other hand, are smallest at this time. In the NAO (+) and NAO (-) years, the SST anomalies and the oceanic heat loss (Figure 6d) are largely out of phase, suggesting that the surface heat flux is an important driver of the SST anomalies. The meridional near-surface current anomalies may additionally contribute to the development of the SST anomalies through the transport of warmer/colder surface water toward the north into the SPG region and colder/warmer surface water toward the south into the STG region. In the NAO (+) years, the northern cell of the overturning dipole anomaly is negative (Figure 6b), which enables development of the negative temperature anomaly over a larger depth range in the SPG region. The regression pattern of the vertically integrated heat content of the upper $500 \mathrm{~m}$ depicts a clear decrease in the SPG region, which like the SST anomalies persists until lag -2 years (Figure S6c). Anomalously high heat content is observed in the midlatitudes from lag 0 to lag 2 years. The succession is very similar after $\mathrm{NAO}(-)$ years with opposite sign of the anomalies (Figure S6).

A particularly important phase of the subdecadal cycle is two years before and after NAO (+), when the atmospheric patterns exhibit hardly any anomalies. The anomalies in SLP (Figure 6a), wind stress curl (Figure 7a), oceanic heat loss (Figure 6d), and the near-surface meridional ocean velocity (Figure 7c) virtually vanish at this time. Thus, the phase reversal in the subdecadal cycle might be initiated by oceanic processes. As noted above, the SST anomaly pattern is well developed two years before (Figure S6c) and after (Figure 6c) NAO (+) but with opposite sign. These phases of the subdecadal variability also are 
a.)

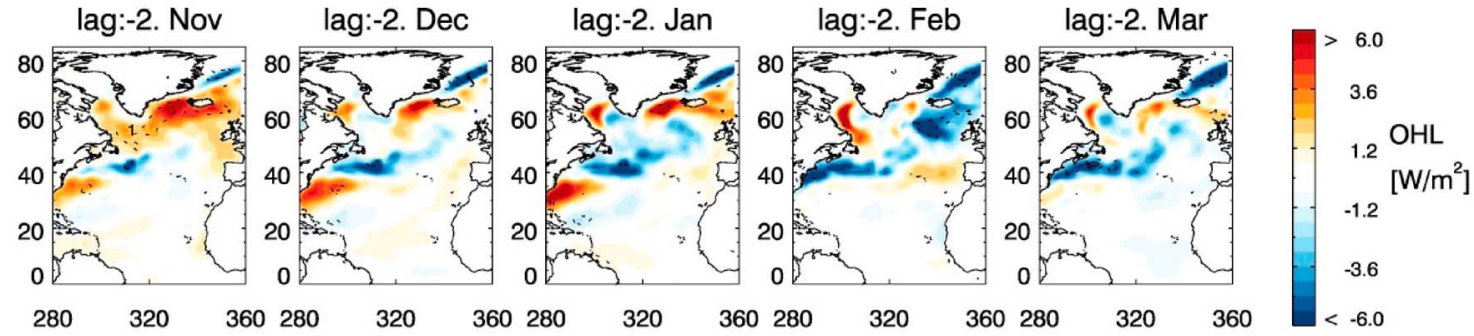

b.)
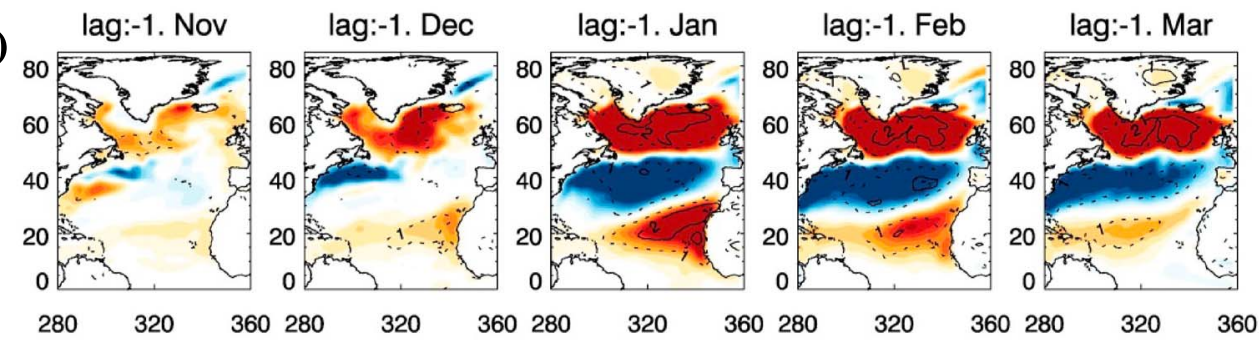

c.)
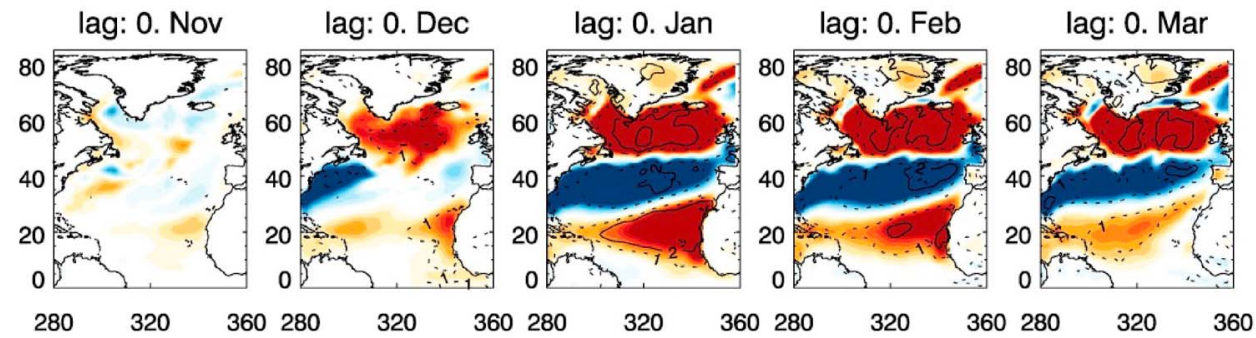

d.)
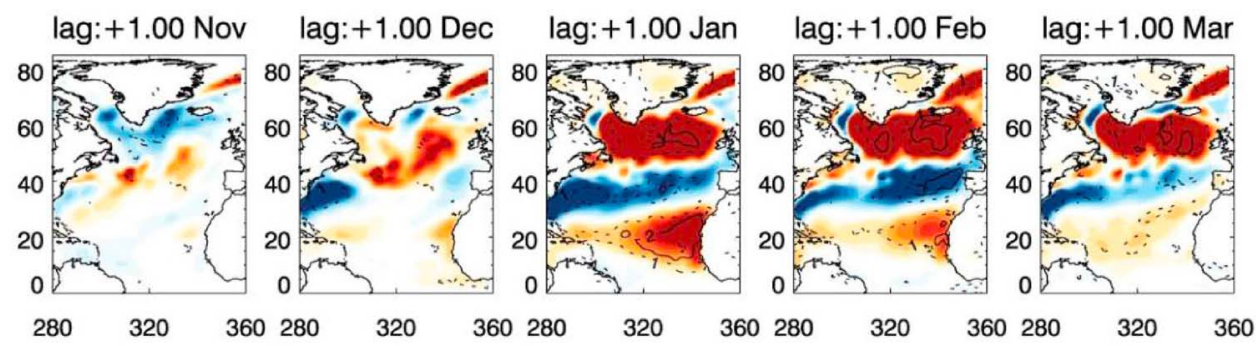

e.)
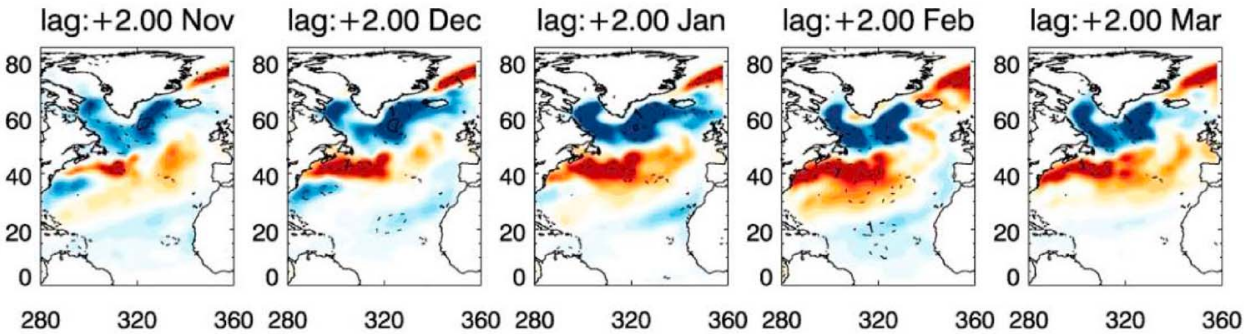

Figure 8. Ensemble-mean lag regression on the NAO index (JFM) of the ocean heat loss during the winter month (November-March) for different lags: (a) two years and (b) one year prior to the NAO maximum, (c) during the winter at NAO maximum, (d) one year, and (e) two years after to the NAO maximum. We note the different color code compared to that in Figure 6d.

characterized by a strong meridional heat content dipole anomaly (Figures S6e and 6e) that already develops two years earlier during the extreme phases of the NAO (lag 0 , lag -4 years). This relationship between the NAO and upper ocean heat content is consistent with the link seen in the corresponding phase spectrum (Figure $4 \mathrm{~b}$ ). Therefore, the heat content could act as a memory and potentially initiate the feedback on the atmosphere and for the subsequent phase reversal of the NAO. 
Let us consider the years prior to NAO (+).The coupling process between the ocean and the atmosphere is visible in the oceanic heat loss (OHL) regression (Figure S6d). At lag -1 year the OHL depicts a dipole pattern linked to the aforementioned dipole in the heat content. For better insight into the exact timing of the atmosphere-ocean heat exchange, the regressions of the OHL are shown in Figure 8 for individual winter months starting two years (Figure 8a) prior to the $\mathrm{NAO}(+)$ maximum. In November of the winter preceding the $\mathrm{NAO}(+)$ maximum (Figure $8 \mathrm{~b}$ ), the OHL is positive in the subpolar region, which corresponds to a heat release to the atmosphere. We hypothesize that this warming of the atmosphere drives a low surface pressure anomaly by enhancing storm activity. In the SPG region, a high-pressure anomaly develops concurrent with the negative OHL anomaly in this region. The resulting dipolar SLP anomaly at lag -1 year (Figure S6a) corresponds to a positive NAO phase. After the NAO (+) maximum, the OHL in the SPG region is still positive in the following late boreal winter (Figure 8d) due to the very low air temperatures (not shown). This might affect the development of low SLP anomalies followed at lag +2 years by a negative OHL (SPG). We conclude that the phase reversal within the subdecadal variability is partly stimulated by the delayed OHL which is due to the oceanic heat content memory.

\section{Summary and Discussion}

We have investigated the variability in the North Atlantic region in preindustrial control integrations of 12 CMIP5 models, with a focus on the subdecadal time scale. A large consistency among the models is found on this time scale, suggesting the significance of subdecadal variability in the North Atlantic sector. In this study, we have derived the ensemble-mean evolution of the subdecadal variability and discuss the common aspects of the underlying mechanism. Variability of the North Atlantic Oscillation (NAO) and the oceanic overturning circulation are at the heart of the mechanism giving rise to the subdecadal variability in North Atlantic sector surface climate. The picture obtained from the CMIP5 models is that the subdecadal variability originates from a coupled interaction of the North Atlantic atmosphere-ocean system.

The NAO is in all models a major part of the atmospheric variability over the North Atlantic. NAO-related wind stress curl variability drives variability in the oceanic overturning circulation on time scales of a decade or shorter. The anomalous overturning represents the integral response to changing wind stress curl and gyre circulation, and drives accumulation/release of the upper ocean heat content. Starting from a negative NAO phase, the adjustment of the overturning circulation causes an accumulation of heat in the subpolar gyre region. This heat is released to the atmosphere in the absence of any NAO forcing, about two years later, forcing a low pressure anomaly over the subpolar latitudes that marks the onset of the positive NAO phase. We argue that the ocean heat content provides a delayed negative feedback, which sets the subdecadal time scale of the coupled mode.

In the coupled climate system of in the North Atlantic region much of the variability originates from stochastic atmospheric forcing. The ocean has the capability to integrate the surface heat flux anomalies and generate lower frequency SST variability. The analysis of the climate model ensemble suggests a feedback between the ocean and the atmosphere on the subdecadal time scale, which contributes a small but significant part of the total variability. The derived mechanism from the CMIP5 models is consistent with surface observations analyzed by Reintges et al. (2017) and also confirms their results derived from a control integration of the Kiel Climate Model. Moreover, the close relation between oceanic heat loss and heat content tendencies in the SPG and STG regions is consistent with the findings of Williams et al. (2014). As the ocean sets the time scale of the subdecadal variability and the dipole SST anomaly is a surrogate for the state of the upper ocean, it may be possible to estimate the overturning dipole anomaly, which is a precursor of surface climate change over the North Atlantic sector, from surface observations themselves. This may open the possibility to enhance multiyear climate predictions in the North Atlantic region provided the model results are realistic.

\section{References}

Allison, L., Hawkins, E., \& Woollings, T. (2015). An event-based approach to understanding decadal fluctuations in the Atlantic meridional overturning circulation. Climate Dynamics, 44(1-2), 163-190. https://doi.org/10.1007/s00382-014-2271-9

ÁlvarezGarcía, F., Latif, M., \& Biastoch, A. (2008). On multidecadal and quasi-decadal North Atlantic variability. Journal of Climate, 21(14), 3433-3452. https://doi.org/10.1175/2007JCLI1800.1 
Barrier, N., Deshayes, J., Treguier, A. M., \& Cassou, C. (2015). Heat budget in the North Atlantic subpolar gyre: Impacts of atmospheric weather regimes on the 1995 warming event. Progress in Oceanography, 130, 75-90. https://doi.org/10.1016/j.pocean.2014.10.001 Bjerknes, J. (1964). Atlantic Air-Sea Interaction. Advances in Geophysics, 10, 1-82. https://doi.org/10.1016/S0065-2687(08)60005-9 Born, A., \& Mignot, J. (2012). Dynamics of decadal variability in the Atlantic subpolar gyre: A stochastically forced oscillator. Climate Dynamics, 39(1-2), 461-474. https://doi.org/10.1007/s00382-011-1180-4

Buckley, M. W., \& Marshall, J. (2016). Observations, inferences, and mechanisms of the Atlantic meridional overturning circulation: A review. Reviews of Geophysics, 54, 5-63. https://doi.org/10.1002/2015RG000493

Cane, M. A., Clement, A. C., Murphy, L. N., \& Bellomo, K. (2017). Low-pass filtering, heat flux, and Atlantic multidecadal variability. Journal of Climate, 30(18), 7529-7553. https://doi.org/10.1175/JCLI-D-16-0810.1

Cunningham, S. A., Kanzow, T., Rayner, D., Baringer, M. O., Johns, W. E., Marotzke, J., et al. (2007). Temporal variability of the Atlantic meridional overturning circulation at 26.5 N. Science, 317(5840), 935-938. https://doi.org/10.1126/science.1141304

Curry, R. G., \& McCartney, M. S. (2001). Ocean gyre circulation changes associated with the North Atlantic Oscillation. Journal of Physical Oceanography, 31(12), 3374-3400.

Czaja, A., \& Marshall, J. (2001). Observations of atmosphere-ocean coupling in the North Atlantic. Quarterly Journal of the Royal Meteorological Society, 127(576), 1893-1916. https://doi.org/10.1002/qj.49712757603

Delworth, T., Manabe, S., \& Stouffer, R. J. (1993). Interdecadal variations of the thermohaline circulation in a coupled ocean-atmosphere model. Journal of Climate, 6(11), 1993-2011. https://doi.org/10.1175/1520-0442(1993)006<1993:IVOTTC>2.0.CO;2

Delworth, T. L., \& Greatbatch, R. J. (2000). Multidecadal thermohaline circulation variability driven by atmospheric surface flux forcing Journal of Climate, 13(9), 1481-1495.

Delworth, T. L., \& Zeng, F. R. (2016). The impact of the North Atlantic Oscillation on climate through its influence on the Atlantic meridional overturning circulation. Journal of Climate, 29, 941-962.

Delworth, T. L., Zeng, F. R., Zhang, L. P., Zhang, R., Vecchi, G. A., \& Yang, X. S. (2017). The central role of ocean dynamics in connecting the North Atlantic Oscillation to the extratropical component of the Atlantic Multidecadal Oscillation. Journal of Climate, 30, 3789-3805.

Deser, C., \& Blackmon, M. L. (1993). Surface climate variations over the North-Atlantic Ocean during winter-1900-1989. Journal of Climate, 6(9), 1743-1753.

Deshayes, J., \& Frankignoul, C. (2008). Simulated variability of the circulation in the North Atlantic from 1953 to 2003. Journal of Climate, 21(19), 4919-4933.

Eden, C., \& Greatbatch, R. J. (2003). A damped decadal oscillation in the North Atlantic climate system. Journal of Climate, 16(24), 4043-4060.

Eden, C., \& Jung, T. (2001). North Atlantic interdecadal variability: Oceanic response to the North Atlantic oscillation (1865-1997). Journal of Climate, 14(5), 676-691.

Gulev, S. K., Latif, M., Keenlyside, N., Park, W., \& Koltermann, K. P. (2013). North Atlantic Ocean control on surface heat flux on multidecadal timescales. Nature, 499(7459), 464-467.

Hurrell, J. W. (1995). Decadal trends in the North-Atlantic Oscillation-Regional temperatures and precipitation. Science, 269(5224), 676-679. https://doi.org/10.1126/science.269.5224.676

Hurrell, J. W., \& Deser, C. (2010). North Atlantic climate variability: The role of the North Atlantic Oscillation. Journal of Marine Systems, 79(3-4), 231-244.

Hurrell, J. W., \& van Loon, H. (1997). Decadal variations in climate associated with the North Atlantic Oscillation. Climatic Change, 36(3-4), 301-326.

Knight, J. R., Allan, R. J., Folland, C. K., Vellinga, M., \& Mann, M. E. (2005). A signature of persistent natural thermohaline circulation cycles in observed climate. Geophysical Research Letters, 32, L20708. https://doi.org/10.1029/2005GL024233

Leith, C. E. (1973). The standard error of time-average estimates of climatic means. Journal of Applied Meteorology, 12(6), $1066-1069$. https://doi.org/10.1175/1520-0450(1973)012<1066:TSEOTA >2.0.CO;2

Lemke, P., Trinkl, E. W., \& Hasselmann, K. (1980). Stochastic dynamic analysis of polar sea ice variability. Journal of Physical Oceanography, 10, 2100-2120.

Marshall, J., Johnson, H., \& Goodman, J. (2001). A study of the interaction of the North Atlantic Oscillation with ocean circulation. Journal of Climate, 14(7), 1399-1421.

Meinshausen, M., Smith, S. J., Calvin, K., Daniel, J. S., Kainuma, M. L. T., Lamarque, J. F., et al. (2011). The RCP greenhouse gas concentrations and their extensions from 1765 to 2300. Climatic Change, 109(1-2), 213-241. https://doi.org/10.1007/s10584-011-0156-Z

Reintges, A., Latif, M., \& Park, W. (2017). Sub-decadal North Atlantic Oscillation variability in observations and the Kiel Climate Model. Climate Dynamics, 48, 3475-3487.

Saravanan, R., \& McWilliams, J. C. (1997). Stochasticity and spatial resonance in interdecadal climate fluctuations. Journal of Climate, 10(9), 2299-2320

Saravanan, R., \& McWilliams, J. C. (1998). Advective ocean-atmosphere interaction: An analytical stochastic model with implications fo decadal variability. Journal of Climate, 11(2), 165-188.

Smeed, D., McCarthy, G., Rayner, D., Moat, B. I., Johns, W. E., Baringer, M. O., \& Meinen, C. S. (2015). Atlantic Meridional Overturning Circulation Observed by the RAPID-MOCHA-WBTS (RAPID-Meridional Overturning Circulation and Heatflux Array-Western Boundary Time Series) Array at $26^{\circ} \mathrm{N}$ from 2004 to 2014. UK: British Oceanographic Data Centre Natural Environment Research Council.

Smeed, D. A., McCarthy, G. D., Cunningham, S. A., Frajka-Williams, E., Rayner, D., Johns, W. E., et al. (2014). Observed decline of the Atlantic meridional overturning circulation 2004-2012. Ocean Science, 10(1), 29-38. https://doi.org/10.5194/os-10-29-2014

Sutton, R. T., \& Allen, M. R. (1997). Decadal predictability of North Atlantic sea surface temperature and climate. Nature, 388(6642), 563-567.

Taylor, K. E., Stouffer, R. J., \& Meehl, G. A. (2012). An overview of CMIP5 and the experiment design. Bulletin of the American Meteorological Society, 93(4), 485-498.

Timmermann, A., Latif, M., Voss, R., \& Grötzner, A. (1998). Northern Hemisphere interdecadal variability: A coupled air-sea mode. Journal of Climate, 11, 1906-1931.

Visbeck, M. H., Hurrell, J. W., Polvani, L., \& Cullen, H. M. (2001). The North Atlantic Oscillation: Past, present, and future. Proceedings of the National Academy of Sciences, 98(23), 12,876-12,877.

Walraven, R. (1985). Digital filters, Proceedings of the Digital Equipment User's Society, Fall 1984, Dep. of Atm. Sci., Uni. of California, Davis, CA 95616.

Williams, R. G., Roussenov, V., Lozier, M. S., \& Smith, D. (2015). Mechanisms of heat content and thermocline change in the subtropical and subpolar North Atlantic. Journal of Climate, 28, 9803-9815. 
Williams, R. G., Roussenov, V., Smith, D., \& Lozier, M. S. (2014). Decadal evolution of ocean thermal anomalies in the North Atlantic: The effects of Ekman, overturning, and horizontal transport. Journal of Climate, 27(2), 698-719.

Yeager, S. (2015). Topographic coupling of the Atlantic overturning and gyre circulations. Journal of Physical Oceanography, 45(5), 1258-1284. https://doi.org/10.1175/JPO-D-14-0100.1

Zhang, J. T., \& Zhang, R. (2015). On the evolution of Atlantic Meridional Overturning circulation fingerprint and implications for decadal predictability in the North Atlantic. Geophysical Research Letters, 42, 5419-5426. https://doi.org/10.1002/2015GL064596

Zhang, R. (2010). Latitudinal dependence of Atlantic meridional overturning circulation (AMOC) variations. Geophysical Research Letters, 37, L16703. https://doi.org/10.1029/2010GL044474 